\title{
EPIDEMIOLOGY OF IRRITABLE BOWEL SYNDROME IN THE FORMER COMMUNIST COUNTRIES FROM EASTERN EUROPE: A SYSTEMATIC REVIEW
}

\author{
FLAVIU RUSU, DAN L. DUMITRASCU
}

\author{
2nd Medical Department, Iuliu Hatieganu University of Medicine and Pharmacy, \\ Cluj-Napoca, Romania
}

\begin{abstract}
Background and aim. The irritable bowel syndrome (IBS) is a functional gastrointestinal disorder frequently encountered in clinical practice in Eastern Europe. Epidemiological data are diverging on this condition. Our objective was to assess the prevalence of IBS in the former communist countries from Eastern Europe (EE).

Methods. We performed a systematic review study using data from PubMed. Many languages, some having only local spreading, are spoken in EE, so we decided to look only for papers indexed in PubMed, which have at least an English summary or title. We searched PubMed using the following keywords: irritable bowel syndrome, functional digestive disorders, prevalence, EE. Only relevant studies were selected for analysis.

Results. From more than 4000 papers retrieved by this search, we identified a few papers appropriate to this survey. The spectrum of prevalence values is wide in IBS. Prevalence of IBS varies in different studies from $28 \%$ in a Croatian study, to $14 \%$ in Romania. Most studies report a higher prevalence in females. Stressful events are linked to the impairment of symptoms. Anxiety and depression are common in IBS patients, showing similar expression of functional symptoms. Quality of life is impaired. The role of abuse (physical, sexual) is not commonly investigated and when it was, the importance of this factor was revealed to be much less important than in Western Europe or North America. General practitioners seem to be well trained to recognize $I B S$, to make correct interpretations of the disease and to use the correct therapy. It seems that the Rome criteria are known and applied by general practitioners. Several epidemiological studies on IBS exist in most EE countries. Usually they look for selfreporting symptoms, or reports from endoscopy units. Psychosomatic approach of IBS was taken into consideration in several countries (Poland, Hungary, Romania), mainly by psychologists and psychotherapists rather than by gastroenterologists.

Conclusions. There are few epidemiological studies on the epidemiology of IBS in EE. The majority of studies used Rome criteria. Several studies used small groups of patients. Some of the smaller studies have methodological flaws. The effect of stress and psychological factors are often investigated and analyzed with different methods of different accuracy. Some doctors used knowledge gained in EE in order to disseminate or to investigate further in more economically developed countries with a higher level of health.
\end{abstract}

Keywords: irritable bowel syndrome, functional gastrointestinal disorders, prevalence, Eastern Europe.

Manuscript received: 01.04.2015

Accepted: 15.04.2015

Address for correspondence: ddumitrascu@umfcluj.ro 


\section{Introduction}

Irritable bowel syndrome (IBS) is one of the most common functional gastrointestinal disorders, a chronic debilitating condition with a reported prevalence of approximately $10 \%$ to $20 \%$ worldwide [ 1,2$]$. However, only $15 \%$ of those affected actually seek medical attention $[3,4]$. IBS accounts for $12 \%$ of primary care patients and $28 \%$ of gastroenterology practice patients (41\% of all functional GI disorders) [4]. IBS is primarily characterized by symptoms like abdominal pain or discomfort associated with an altered bowel function in the absence of any organic cause. Patients commonly report abnormal defecation ranging from diarrhoea to constipation, including a combination of the two, the degree of which can vary in both duration and severity $[5,6]$. The symptoms are troublesome and affect the quality of life and work capacity of patients, which can increase the risk of depression and social isolation $[7,8]$.

IBS is part of the gastrointestinal disorders frequently encountered in clinical practice in EE, and is considered important to public health because it raises important social and economic issues. IBS patients are a frequently debated topic today. Morbidity is diverse, depending on age and sex, although occupation and culture may also have an important influence.

Studies conducted in Western Europe showed a prevalence of IBS between 10-15\%. Based on studies conducted in Western Europe, IBS is believed to spread both west and east, with no significant difference of the prevalence [9]. Since in the last 20 years several studies have been published regarding the prevalence of IBS in EE, we can compare both criteria for IBS and results with those from Western Europe. In addition, knowing the prevalence of IBS it can be estimated how the disease will consume medical resources in society.

Currently, most studies on the prevalence of IBS are developed on the basis of questionnaires distributed to patients [10-12].

$\mathrm{EE}$ is a volatile geographical-political-social construct. Geographically this represents an area situated in the eastern part of the old continent, prolonged (due to the transcontinental position of Turkey and Russia, including former USSR) to Central Asia, and from the Baltic Sea to the Black Sea and Eastern Mediterranean Sea. Many call this area Central and East Europe (CEE) considering EE the former soviet space including Transcaucasia and Central Europe the countries deriving from the former communist block.

EE is a large geographical area populated by nations of different origins: East, West and Southern (Slaves), Baltic (Latvians and Lithuanians), Latin (Romanians),
Ugro-finnic (Estonians and Hungarians), Turkic (Turks, Azeri), Greeks, Armenians, Georgians. The inhabitants of EE had different history, political status and economical standards.

In this study we decided to analyze data from former communist countries in order to cover a larger area.

\section{Methods}

We performed a systematic review study using data from PubMed till 2012. We selected only PubMed indexed papers, papers which had abstract or at least the title in English. All others papers were excluded. We searched on the PubMed these keywords: irritable bowel syndrome, functional digestive disorders, prevalence, Eastern Europe. Only relevant studies were selected for analysis. We started from a total of 4607 PubMed indexed papers on gastrointestinal pathology published in Eastern Europe. Participants in this study were patients diagnosed with IBS in EE. Most studies used Rome criteria for diagnosis of IBS. No papers were selected from Russia and the former Baltic countries because the results of IBS prevalence in these former communist countries has been the subject of another research study (Sperber et al, to be submitted).

We analyzed the results published in each former communist country, then comparing them with the results from all former communist countries. We analyzed following parameters: stress, mental disorders, knowledge of physicians in recognizing IBS symptoms, personality traits level, food and nutrition.

Statistical methods: we used SPSS version 22.0 for Windows.

\section{Results}

We analyzed 4607 PubMed indexed papers. The number of papers containing organic pathology and functional gastrointestinal disorders is represented in Table I. In terms of functional gastrointestinal disorders, the papers classification is represented in Table II.

Distribution by EE countries on functional gastrointestinal disorders is represented in Fig. 1. One paper is actually a multinational study including also patients from Italy, Germany and Spain. Of the total of 19 papers regarding functional gastrointestinal disorders, the largest number of papers was from Poland and Hungary (10 papers, 5 from Poland and 5 from Hungary).

From more than 4000 papers retrieved by this search from PubMed on gastrointestinal pathology in EE, we identified only 10 full papers related to IBS (Fig. 2). Of the total of 10 papers regarding IBS, the largest number of papers (4 papers) was from Poland. Most studies used

Table I. Analyzed papers.

\begin{tabular}{lll}
\hline Total numbers of the analyzed papers & Papers related to organic pathology & Papers related to functional pathology \\
\hline 4607 & 4588 & 19 \\
\hline
\end{tabular}


Table II. The classification of the functional gastrointestinal disorders papers.

\begin{tabular}{|c|c|c|c|c|c|c|}
\hline IBS & $\begin{array}{l}\text { functional } \\
\text { dyspepsia }\end{array}$ & $\begin{array}{l}\text { functional } \\
\text { constipation }\end{array}$ & $\begin{array}{l}\text { functional dyspepsia } \\
\text { and functional reflux }\end{array}$ & $\begin{array}{l}\text { functional } \\
\text { reflux }\end{array}$ & $\begin{array}{c}\text { functional } \\
\text { dyspepsia and IBS }\end{array}$ & $\begin{array}{l}\text { functional GI } \\
\text { disorders }\end{array}$ \\
\hline 9 & 3 & 2 & 1 & 2 & 1 & 1 \\
\hline
\end{tabular}

\section{Distribution of the functional gastrointestinal disorders papers by countries}

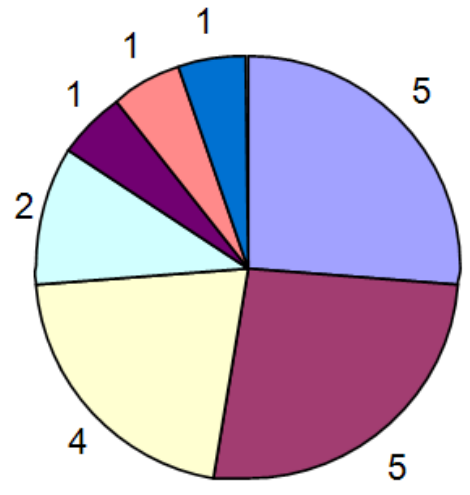

Figure 1. Distribution of the functional gastrointestinal disorders papers by country.
Poland

Hungary

$\square$ Romania

$\square$ Croatia

Bulgaria

Czech Republic

including subjects from Hungary,

Poland, Germany, Italy, Spain

\section{No of IBS papers}

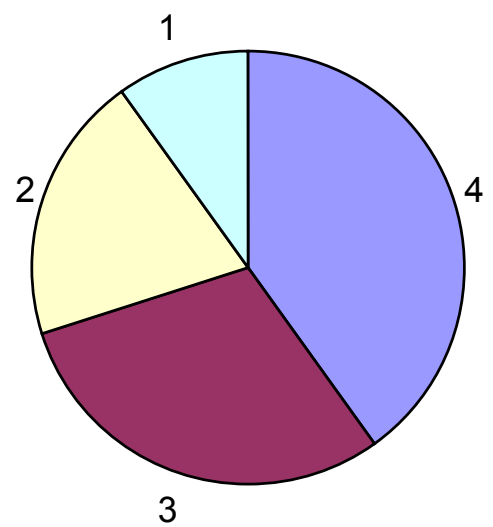

$\square$ Poland

Romania

$\square$ Hungary

$\square$ Croatia

Figure 2. Number of IBS full papers by countries.

Table III. Analysis of the IBS papers concerning studied topics.

\begin{tabular}{llll}
\hline Studied topic & No & Country & \\
\hline Stress & 2 & Romania & Hungary \\
Psychiatric disorders & 3 & Romania & Hungary \\
Training of GPs & 1 & Pomania & \\
Food and nutrition & 1 & Poland \\
Body mass index & 1 & Croatia & \\
\hline
\end{tabular}


Rome criteria for the diagnosis of IBS. Analysis of the IBS papers concerning studied topics is represented in Table III.

Numerous studies have been limited to a group of patients. Many studies have been performed on hospitalized patients. The prevalence of IBS varies in different studies. Most studies report a higher prevalence in women.

In Romania three studies on IBS were published. Dumitrascu DL was the first author from Romania who published in Med War journal results of a study on IBS patients in 1991. The subject of the study was the IBS complaints following the uprising of December 1989 in Romania. The conclusions of the study showed an increased amount of irritable-bowel-like symptoms within the first month following the uprising in Romania in December 1989. These symptoms seem to be related to the impressive amount of stress developed by dramatic events presented live on television and watched by the population. Several new cases as compared to the previous year were also reported by his group for the study of psychogenic factors in irritable bowel syndrome.

Drug et al. published in Rev Med Chir Soc Med Nat Iasi 2002 a paper which aimed at studying the relationship between functional digestive disorders and psychiatric diseases. Their results showed that the prevalence of IBS symptoms in the general population was: $14.4 \%(8.4 \%$ in males and $17.7 \%$ in females). Psychiatric positive history was present in $6.2 \%$ of the general population and in $6.1 \%$ of IBS subjects ( $p>0.05)$. Psychiatric disorders were more common in the IBS subjects who were seeking medical assistance (18\%) than in subjects with same symptoms from the general population $(6.2 \%)(\mathrm{p}<0.05)$. The conclusion was that psychiatric disorders may influence the medial referral for patients with IBS.

Dumitrascu et al. published in J Gastrointestin Liver Dis. 2006 a paper which aimed at studying what general practitioners from a Romanian province know about IBS. One hundred GPs were invited to a two hour, free, updating course on IBS. The participants were asked to fill a questionnaire before and after the course, which comprised questions about medical experience, demography, and several multiple-choice questions about GPs opinions and awareness. The final question assessed the estimated prevalence of IBS in the practice. Full responses to both questionnaires were obtained from all attending GPs $(\mathrm{n}=88)$. They were 25 males: 63 females, with working experience between 3 and 41 years (mean +/- SD: $24+/-11$ ). Apart from $2(2.4 \%)$ who indicated that IBS is a motility disorder (opinion revised after the course), all other GPs considered IBS as a functional disorder. All (100\%) opted for the necessity of colonoscopy to diagnose IBS. $98.8 \%$ indicated the use of Rome II criteria for the diagnosis of IBS (this survey was done before the availability of Rome III but their advent was mentioned). All (100\%) had participated in previous lectures or courses on IBS. $58(66 \%)$ reported the prevalence of IBS in their practice between $1-10 \%$; 16 (18\%) between 10-25\%; 11 (12.5\%) between $25-33 \%$; $3(3.5 \%)$ reported $<1 \%$. The conclusion was that the investigated GPs seemed to be well trained in recognizing IBS. The majority (66\%) estimated the prevalence of this condition as $1-10 \%$ in their practice.

From Poland we found 4 papers on IBS. Unfortunately, none of the papers has a detailed description of the study characteristics. Wrzesińska MA published in Psychiatr Pol. 2008 the study results which aimed to research the assessment of personality traits and coping style level among the patients with functional dyspepsia and irritable bowel syndrome. The conclusion was that the lack of an effective coping is characteristic for patients with functional dyspepsia and irritable bowel syndrome. Significant differences between groups were noted in the conscientiousness level. Patients with functional dyspepsia had a high level and patients with irritable bowel syndrome an average level of conscientiousness. Two papers from Poland published on PubMed have only title of the papers $[13,14]$.

In Hungary two papers on IBS were published. Seres et al. published in J Clin Psychol Med Settings 2008 the results of a study that had as goal the research of the different associations of health related quality of life with pain, psychological distress and coping strategies in patients with irritable bowel syndrome and inflammatory bowel disorder. The results showed that IBS patients had significantly higher levels of psychological distress, pain severity and maladaptive pain coping strategies (catastrophization), and lower QOL than UC patients. Variance of QOL in IBS was explained for the most part by catastrophization (15\%), then by psychological distress $(8 \%)$, and for the less part by pain severity $(5 \%)$. In UC, pain severity explained $21 \%$, psychological distress $8 \%$, and catastrophization 3\% of the variance of QOL. These results suggest there are differences between IBS and UC patients in the role of physical and psychological factors in QOL and emphasize the importance of cognitive processes in IBS.

In Croatia only one paper regarding IBS was published. Baretić et al. published in Coll Antropol 2002 the results of the study which aimed to research the epidemiology of irritable bowel syndrome in Croatia. Study results showed a high prevalence of IBS: i.e. $28 \%$ ( $10 \%$ of males and $18 \%$ of females). Age, education and urban/rural type of living were not related to the prevalence of IBS. Logistic regression gave gender-body mass index (BMI) model for IBS determination: the relative risk for getting IBS in females was by $165 \%$ higher than in males and BMI increase of $5 \mathrm{~kg} / \mathrm{m} 2$ increased the risk of IBS by $36 \%$. BMI was indicated as a possible new factor of IBS prevalence. 


\section{Discussion}

Population-based studies estimate the prevalence of irritable bowel syndrome at $10-20 \%$ and the incidence of irritable bowel syndrome at $1-2 \%$ per year. From all the patients with irritable bowel syndrome, approximately $10-20 \%$ seek medical care. An estimated $20-50 \%$ of gastroenterology referrals relate to this symptom complex. The incidence is markedly different among countries. American and European cultures demonstrate similar frequencies of irritable bowel syndrome across racial and ethnic lines. In Western countries, women are 2-3 times more likely to develop irritable bowel syndrome than men, although males represent $70-80 \%$ of patients with irritable bowel syndrome in the Indian subcontinent. Women seek health care more often, but the irritable bowel syndrome - specific influence of this occurrence remains unknown [15].

In the studied papers, stress was a common component in patients with IBS [16,17]. Stress affects the clinical status of patients, influencing the degree of perception of pain and quality of life of these patients. Psychiatric disorders were also common in patients with IBS, being able to affect the degree of addressability to the doctor of those patients [18]. Patients with IBS have a higher degree of depression and anxiety compared to healthy patients [19]. Physicians in Romania seem to be well trained in recognizing IBS, most of them (66\%) estimating the prevalence of about $10 \%$ of this disease in their practice [20]. Personality traits level (neuroticism, extraversion, openness to experiences, agreeableness, conscientiousness) are altered in patients with IBS [21]. Food and nutrition influence clinical status of patients with IBS [22]. This was analyzed later in a variety of studies. Increased body mass index was associated with a higher incidence of IBS, being indicated as a possible new prevalence IBS factor [23].

We can say that there was a concern of physicians regarding IBS in EE. Most of the studies used Rome criteria. Some studies used small groups of patients and had methodological shortcomings. The effect of stress and psychological factors are often investigated and analyzed with different methods of different accuracy. Some doctors used knowledge gained in $\mathrm{EE}$ in order to disseminate or to further investigate in more economically developed countries with a higher level of health.

\section{Conclusions}

Most of the studies are limited in size due to difficulty in obtaining funds for such a "non-priority" pathology as IBS. Prevalence of IBS varies in different studies from $28 \%$ in Croatia to $14 \%$ in Romania. Most studies report a higher prevalence in females. Stressful events are linked to the aggravation of symptoms. Anxiety and depression are common in IBS patients, showing similar expression of functional symptoms. Quality of life is impaired. The general practitioners seem to be well trained to recognize IBS, make correct interpretations of the condition and use correct therapies. Epidemiological studies on IBS exist in most EE countries. Usually they look for self-reporting symptoms, or reports from endoscopy units. Psychosomatic approach of IBS is taken in consideration in several countries (Poland, Hungary, Romania) mainly by psychologists and psychotherapists than by gastroenterologists.

More light will be shed by a paper by Sperber et al, to be submitted. This paper will more comprehensively look to epidemiology of IBS in all EE area, including postsoviet and South-East countries.

\section{References}

1. Saito YA, Schoefeld P, Locke GR 3rd. The epidemiology of irritable bowel syndrome in North America: a systematic review. Am J Gastroenterol. 2002;97:1910-1915.

2. Gwee K-A. Irritable bowel syndrome in developing countries - a disorder of civilization or colonization? Neurogastroenterol Motil. 2005; 17:317-324.

3. Canavan C, West J, Card T. The epidemiology of irritable bowel syndrome. Clin Epidemiol. 2014;6:71-80.

4. Drossman DA, Camilleri M, Mayer EA, Whitehead WE. AGA technical review on irritable bowel syndrome. Gastroenterology. 2002;123:2108-2131.

5. Agréus L, Svärdsudd K, Nyrén O, Tibblin G. Irritable bowel syndrome and dyspepsia in the general population: overlap and lack of stability over time. Gastroenterology. 1995;109:671-680.

6. Drossman DA, Morris CB, Hu Y, Toner BB, Diamant N, Leserman $\mathrm{J}$, et al. A prospective assessment of bowel habit in irritable bowel syndrome in women: defining an alternator. Gastroenterology. 2005;128:580-589.

7. Devanarayana NM, Mettananda S, Liyanarachchi C, Nanayakkara N, Mendis N, Perera N, et al. Abdominal painpredominant functional gastrointestinal diseases in children and adolescents: prevalence, symptomatology, and association with emotional stress. J Pediatr Gastroenterol Nutr. 2011;53:659-665.

8. Zhou H, Yao M, Cheng GY, Chen YP, Li DG. Prevalence and associated factors of functional gastrointestinal disorders and bowel habits in Chinese adolescents: a school-based study. J Pediatr Gastroenterol Nutr. 2011;53:168-173.

9. Kang JY. Systemic review: the influence of geography and ethnicity in irritable bowel syndrome. Aliment Pharmacol Ther. 2005;21:663-676.

10. Guilera M, Balboa A, Mearin F. Bowel habit subtypes and temporal patterns in irritable bowel syndrome: systematic review. Am J Gastroenterol. 2005;100:1174-1184.

11. Spiller R, Aziz Q, Creed F, Emmanuel A, Houghton L, Hungin $\mathrm{P}$, et al. Guidelines on the irritable bowel syndrome: mechanisms and practical management. Gut. 2007;56:1770-1798.

12. Hillilä MT, Färkkilä MA. Prevalence of irritable bowel syndrome according to different diagnostic criteria in a nonselected adult population. Aliment Pharmacol Ther. 2004;20:339345.

13. Kopylow A, Marlicz K, Cwajda H, Majewska M. Irritable colon with reference to three clinics of internal diseases in Szczecin . Przegl Lek. 1975;32(8):637-640.

14. Tuszkiewicz AR, Zatońska I. Irritable colon in patients of the 2d Department of Internal Diseases of the Medical Academy in 
Lublin in 1961-1965. Pol Tyg Lek. 1967;22(1):16-18.

15. Jenifer K Lehrer. Irritable Bowel Syndrome. MEDSCAPE [Updated: Jan 12, 2015]

16. Dumitrascu DL, Baban A. Irritable bowel syndrome complaints following the uprising of December 1989 in Romania. Med War. 1991;7(2):100-104.

17. Seres G, Kovács Z, Kovács A, Kerékgyártó O, Sárdi K, Demeter $P$, et al. Different associations of health related quality of life with pain, psychological distress and coping strategies in patients with irritable bowel syndrome and inflammatory bowel disorder. J Clin Psychol Med Settings. 2008;15(4):287-295.

18. Drug VL, Costea F, Ciochină AD, Brădăţan O, Taraşi I, Mitrică $\mathrm{D}$, et al. Functional digestive disorders and the relationship with psychiatric diseases. Rev Med Chir Soc Med Nat Iasi. 2002;107(2):307-310.

19. Kovács Z, Kovács F. Depressive and anxiety symptoms, dysfunctional attitudes and social aspects in irritable bowel syndrome and inflammatory bowel disease. Int J Psychiatry Med. 2007;37(3):245-255.

20. Dumitrascu DL, David L, Singer M. What general practitioners know about irritable bowel syndrome. Preliminary data from a Romanian province. Preliminary data from a Romanian province. J Gastrointestin Liver Dis. 2006;15(3):227-30.

21. Wrzesińska MA, Kocur J. The assessment of personality traits and coping style level among the patients with functional dyspepsia and irritable bowel syndrome. Psychiatr Pol. 2008;42(5):709-717. 22. Hayes PA, Fraher MH, Quigley EM. Irritable Bowel Syndrome: The role of food in pathogenesis and management. Gastroenterol Hepatol (N Y) 2014;10(3):164-174.

23. Baretić M, Bilić A, Jurcić D, Mihanović M, Sunić-Omejc M, Dorosulić Z, et al. Epidemiology of irritable bowel syndrome in Croatia. Coll Antropol. 2002;26 Suppl:85-91. 